\title{
Assessment of diabetes control in a primary care setting, Riyadh
}

\author{
Thamer Alsulaiman \\ Correspondence: alsth829@hotmail.com

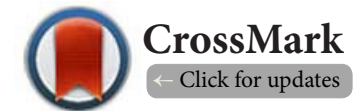

Department of Family Medicine, National Guard Hospital, Riyadh, Saudi Arabia.

\begin{abstract}
Aim: The aim of this audit was to assess the level of control of diabetes at "Aohud" primary care clinic during the year 2014.

Methods: In June 2014, diabetic patients at Aohud clinic, Riyadh were identified from our chronic conditions database and their computerized medical records were reviewed. Glycated haemoglobin levels (HbA1c), Blood pressure (BP), and Low-density lipoprotein levels (LDL) were noted and patients were categorized accordingly. The standard set for this audit was for $75 \%$ of diabetics to have an $\mathrm{HbA} 1 \mathrm{c}$ less than $8 \%$, a Blood pressure (BP) less than 140/90 mmhg, and an LDL less than $2.6 \mathrm{mmol} / \mathrm{l}$.

Results: Out of the 116 diabetics reviewed, $48.3 \%$ had an HbA1c level above $8 \%, 42.2 \%$ had an LDL level above $2.6 \mathrm{mmol} / \mathrm{l}$, and $15.5 \%$ had a $\mathrm{BP}$ above $140 / 90 \mathrm{mmhg}$.

Conclusions: Although the majority of diabetics at Aohud clinic had their blood pressure under control (84.5\%), a large number of them had uncontrolled diabetes (48.3\%) and dyslipidemia (42.2\%). More work needs to be done in order to better control diabetes at Aohud clinic. Initiating a recall system might help achieve the recommended targets.
\end{abstract}

Keywords: Diabetes, glycaemic control, primary care, blood pressure

\section{Introduction}

Diabetes mellitus is a complex chronic condition and a worldwide health burden $[1,2]$. In Saudi Arabia, the prevalence rate of diabetes has been reported to be as high as $23.7 \%$ [3]. Diabetes management can be challenging and involves glycemic control as well as management of co-existing risk factors (e.g., hypertension and dyslipidemia) in order to reduce complications [1]. Diabetic complications include retinopathy, nephropathy, neuropathy, and cardiovascular disease [4].

A problem faced at Aohud primary care clinic is frequent "uncontrolled diabetics" who are being seen. This study will examine diabetics' control (glycaemic control, co-existing dyslipidemia and hypertension) and compare it to a defined standard (American Diabetes Association (ADA) and eighth Joint National Committee (JNC8) guidelines). Our objective was to identify deficiencies in our practice to help planning for future improvements and targeting those at high risk.

\section{Subjects and methods}

Aohud clinic was one of eleven primary care clinics at King
Abdulaziz Housing City. The clinic was a "walk-in" clinic serving about 3700 registered patients. It had a database classifying chronic conditions among registered patients (e.g., Diabetes, hypertension) and diabetic patients attended on "as needed" basis with no active recall system in place. During June 2014, all patients classified with " diabetes" on Aohud's listed chronic conditions database were identified and their computerized notes were reviewed. Glycated haemoglobin levels ( $\mathrm{HbA1c}$ ), Blood pressure (BP), and Low-density lipoprotein levels (LDL) were noted and patients were categorized accordingly. For the purpose of this audit, uncontrolled diabetes was defined as having an $\mathrm{HbA} 1 \mathrm{C}$ above $8 \%$, dyslipidemia was defined as having an LDL equal or above $2.6 \mathrm{mmol} / \mathrm{l}$ and uncontrolled hypertension was defined as having a blood pressure equal or more than 140/90 mmhg. The standard set for this audit was for three quarters $(75 \%)$ of diabetics to have an $\mathrm{HbA} 1 \mathrm{c}$ less than $8 \%$, a blood pressure less than 140/90 mmhg, and an LDL level less than $2.6 \mathrm{mmol} / \mathrm{l}$. American Diabetes Association and Joint National Committee-8 guidelines were used as a reference in setting the targets of this study and comparing our results. 
Thamer Alsulaiman, Family Practice Reports 2015,

Inactive patients (i.e., not seen for more than two years) were excluded from our study. Patients with nephropathy or co-existing cardiovascular disease were not specifically examined in this audit. Data entry and analysis were done by the author. Approval for conducting this audit (including ethical consideration) was issued through King Abdullah International Medical Research Center.

\section{Results}

Out of the 144 diabetics identified at Aohud clinic, 116 active diabetics were included in our study while 28 diabetics were inactive and were excluded. $48.3 \%$ of diabetics at A3 clinic were found to have uncontrolled diabetes, $25 \%$ of them had an $\mathrm{HbA} 1 \mathrm{c}$ between 7 and $8 \%$, and $26.7 \%$ of them had their diabetes under control (HbA1c $<7 \%$ ) (Figure 1). $42.2 \%$ of diabetics had dyslipidemia with an LDL level above 2.6 while $57.8 \%$ had their LDL levels below 2.6 (Figure 2). $72.5 \%$ of diabetics had their blood pressure (BP) below 130/80, $12 \%$ had a (BP) between 130/80-140/90 while only $15.5 \%$ had their (BP) above 140/90 (Figure 3). The majority of diabetics were of type-two diabetes $(96.5 \%), 55.2 \%$ were females and all of them were of Saudi nationality.

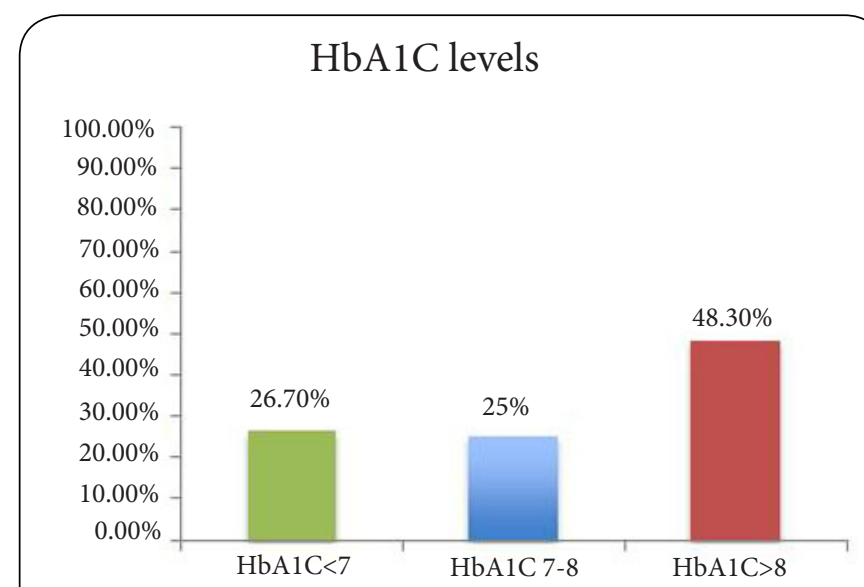

Figure 1. Glycaemic control among diabetics $(\mathrm{N}=116)$.

\section{Discussion}

In this audit the main goal was to examine diabetes control at Aohud clinic. Three parameters were examined, namely: HBA1c, LDL and blood pressure. Almost half of diabetics at Aohud clinic (48.3\%) had uncontrolled diabetes with an HbA1c above $8 \%$. Similar results (54\%) have been reported by Al-Hussein in a study looking at diabetics in primary care setting while using $8.4 \%$ for defining uncontrolled diabetes [5]. The rate of controlled diabetes $(\mathrm{HbA} 1 \mathrm{c}<7 \%$ ) in our study was $26.7 \%$. This compares well to other local studies, which have reported rates between $10-20 \%[5,6]$. On the other hand, our rate of uncontrolled diabetics seems much higher than international figures. For example, Harris et al., reported a rate of only $17 \%$ for uncontrolled diabetes in Canadian primary
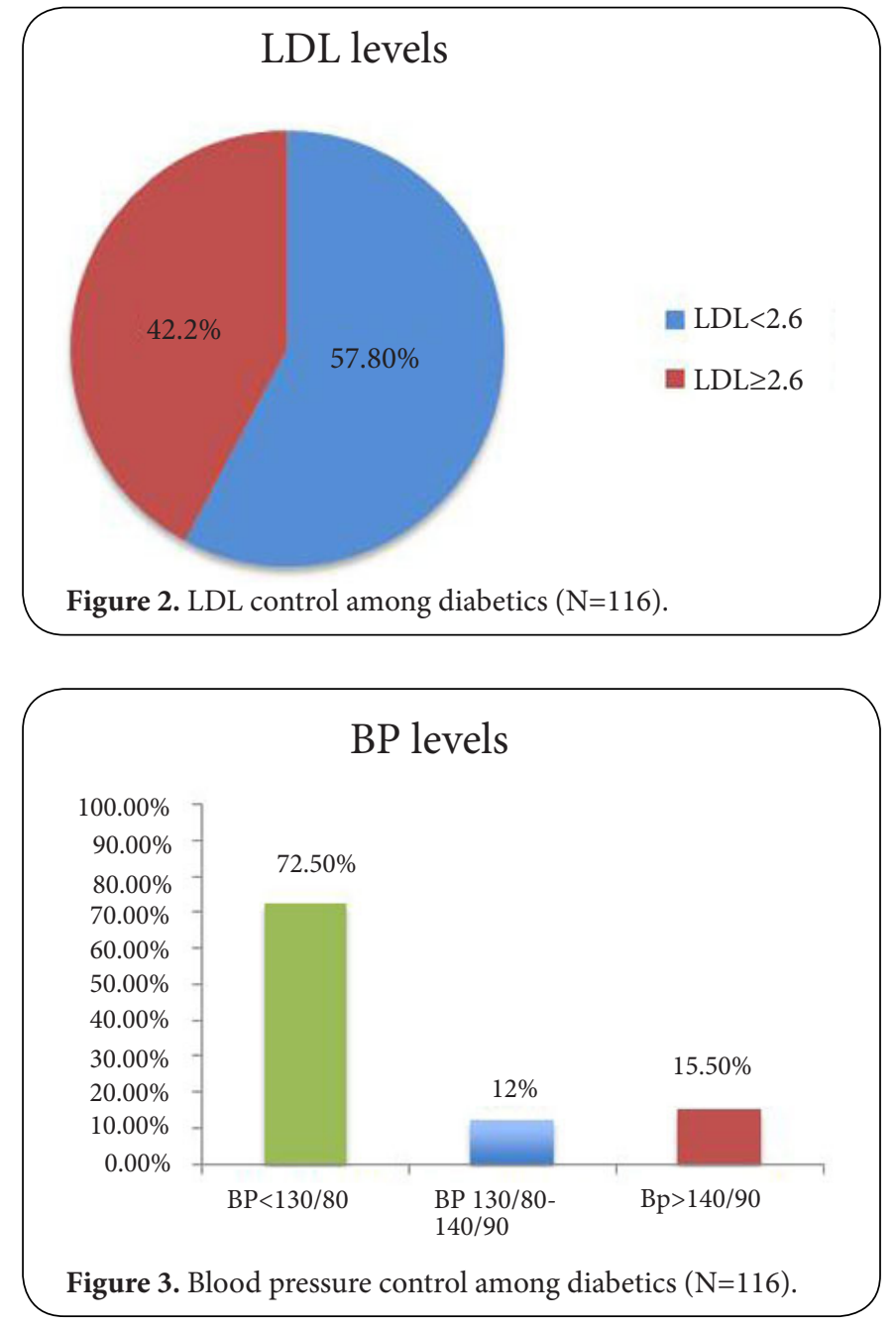

care setting [7]. However, a higher threshold ( $\mathrm{HbA} 1 \mathrm{c}>8.4 \%)$ was used to define "inadequate control" in their report. Several factors serve as barriers to achieving optimal glycaemic control. These include: non-compliance to diet and exercise advice, lack of interest and knowledge, non-compliance with medication regimen, as well as cultural barriers [7]. In our study, a large number of patients, although registered in our clinic and who attend from time to time, live outside of King Abdulaziz Housing City and therefore miss some of their scheduled follow-up appointments. Moreover, some diabetics stop taking or self-adjust their medications when experiencing hypoglycemic-episodes without consulting their doctor. Furthermore, patients' next of kin commonly attend for medication refills on behalf of the actual patient and as a result, doctors miss the chance for reviewing and adjusting diabetic patients medications. This is besides doctor factors that include hesitancy in initiating and intensifying insulin for uncontrolled diabetics, a common problem for physicians dealing with diabetics in a primary care setting [8] $84.5 \%$ of diabetics at Aohud clinic had their blood pressure below $140 / 90$ and of these $72.5 \%$ had a blood pressure below $130 / 80$, 
which meets our standard for this audit. The above rate has also included diabetics without known hypertension. This may have overestimated our results, nevertheless; the measured blood pressure for diabetics in our clinic was within target. The rate of controlled hypertension in diabetics attending local primary care clinics has been previously reported as about $16 \%$ [6]. Only $15.5 \%$ of diabetics had a blood pressure above $140 / 90$, which needs attention to meet the recommended guidelines [9]. 57.8\% of our diabetics had an LDL below 2.6, which meets the ADA guidelines for managing dyslipidemia in diabetics [1]. However, a large number (42.2\%) of diabetics had uncontrolled dyslipidemia at the time of running this audit. Although a high rate, it is lower than other local reports [6]. Patient factors (non-compliance) and doctor factors (non-escalation of treatment) could have contributed to this result. Interventions targeting follow-up arrangements can improve diabetic outcomes [10]. A recall system to follow up uncontrolled diabetics can therefore be of value.

\section{Conclusion and recommendations}

Although the majority of diabetics at Aohud clinic have their blood pressure under control, a large number of them have uncontrolled diabetes and dyslipidemia. More work needs to be done in order to better control diabetes at Aohud clinic. Initiating a recall system as well as a strict refill medication policy might help achieve the recommended targets.

\section{Competing interests}

The author declares that he has no competing interests.

\section{Acknowledgement}

Dr. Ahmed Mahmoud and Dr. Intisar Fadlallah for their contribution in developing a listed chronic conditions database at Aohoud clinic.

KAIMRC and Family medicine department at NGHA for their support.

\section{Publication history}

Editors: Yahia Mater Al-Khaldi, Ministry of Health, Saudi Arabia. Soornarain Subramoney Naidoo, Durban University of Technology, South Africa.

Senior Editor: Waris Qidwai, Aga Khan University, Pakistan.

Received: 01-May-2015 Final Revised: 20-Jun-2015

Accepted: 23-Jun-2015 Published: 02-Jul-2015

\section{References}

1. American Diabetes Association. Standards of Medical Care in Diabetes-2014. Diabetes Care 2014; 37:14-80. | Article

2. Del Prato S, Felton AM, Munro N, Nesto R, Zimmet $P$ and Zinman $B$. Improving glucose management: ten steps to get more patients with type 2 diabetes to glycaemic goal. Int J Clin Pract. 2005; 59:1345-55. | Article | PubMed

3. Al-Nozha MM, Al-Maatouq MA, Al-Mazrou YY, Al-Harthi SS, Arafah MR, Khalil MZ, Khan NB, Al-Khadra A, Al-Marzouki K, Nouh MS, Abdullah M, Attas O, Al-Shahid MS and Al-Mobeireek A. Diabetes mellitus in Saudi Arabia. Saudi Med J. 2004; 25:1603-10. | PubMed

4. Fowler M. Microvascular and Macrovascular Complications of Diabetes. Clinical Diabetes 2008; 26:77-82. | Article

5. Al-Hussein FA. Diabetes control in a primary care setting: a retrospective study of 651 patients. Ann Saudi Med. 2008; 28:267-71. | Article | PubMed

6. Guzu A, Al Shehri A, Al Khashan H and Mishriky A. Quality of Care for Type 2 Diabetes Mellitus in a Military Primary Care Setting.J Clin Outcomes Manage. 2012; 19:551-56. | Pdf

7. Harris SB, Ekoe JM, Zdanowicz Y and Webster-Bogaert S. Glycemic control and morbidity in the Canadian primary care setting (results of the diabetes in Canada evaluation study). Diabetes Res Clin Pract. 2005; 70:90-7. | Article | PubMed

8. Ziemer DC, Miller CD, Rhee MK, Doyle JP, Watkins C, Jr., Cook CB, Gallina DL, El-Kebbi IM, Barnes CS, Dunbar VG, Branch WT, Jr. and Phillips LS. Clinical inertia contributes to poor diabetes control in a primary care setting. Diabetes Educ. 2005; 31:564-71. | Article | PubMed

9. James PA, Oparil S, Carter BL, Cushman WC, Dennison-Himmelfarb C, Handler J, Lackland DT, LeFevre ML, MacKenzie TD, Ogedegbe O, Smith SC, Jr., Svetkey LP, Taler SJ, Townsend RR, Wright JT, Jr., Narva AS and Ortiz E. 2014 evidence-based guideline for the management of high blood pressure in adults: report from the panel members appointed to the Eighth Joint National Committee (JNC 8). JAMA. 2014; 311:507-20. | Article | PubMed

10. Renders CM, Valk GD, Griffin SJ, Wagner EH, Eijk Van JT and Assendelft WJ. Interventions to improve the management of diabetes in primary care, outpatient, and community settings: a systematic review. Diabetes Care. 2001; 24:1821-33. | Article | PubMed

\section{Citation:}

Alsulaiman T. Assessment of diabetes control in a

primary care setting, Riyadh. Fam Pract Rep. 2015; 2:1. http://dx.doi.org/10.7243/2056-5690-2-1 